\title{
Using Sports Tracker: Evidences on Dependence, Self-Regulatory Modes and Resilience in a Sample of Competitive Runners
}

\author{
Pierluigi Diotaiuti* ${ }^{(0)}$, Stefania Mancone, Stefano Corrado \\ Department of Human Sciences, Society and Health, University of Cassino and Southern Lazio, Cassino, Italy \\ Email: ${ }^{*}$.diotaiuti@unicas.it
}

How to cite this paper: Diotaiuti, P., Mancone, S., \& Corrado, S. (2020). Using Sports Tracker: Evidences on Dependence, Self-Regulatory Modes and Resilience in a Sample of Competitive Runners. Psychology, 11, 54-70.

https://doi.org/10.4236/psych.2020.111005

Received: December 1, 2019

Accepted: January 5, 2020

Published: January 8, 2020

Copyright $\odot 2020$ by author(s) and Scientific Research Publishing Inc. This work is licensed under the Creative Commons Attribution International License (CC BY 4.0).

http://creativecommons.org/licenses/by/4.0/

\begin{abstract}
A sample of 111 runners was given a survey to illustrate their experience in using sports monitoring devices. Competitive experience proved to be a determining variable in influencing the strategy of using digital devices, suggesting a specific ergonomic model, so that the functionalities of sport trackers were first discovered, then consolidated and finally subjected to a rigorous selection. A relatively more passive and dependent attitude towards the monitoring tools in competitive running was found in subjects with less competitive experience $(p<.05)$, less personal resilience $(p<.01)$, less target orientation $(p<.0001)$. The more experienced runners, on the other hand, have shown that over time they have acquired a progressive mastery and internal control of their performance functions, so that they were sufficiently autonomous to structure the relationship of use with the sport trackers in a strictly instrumental way, for which there was no perception of dependence or submission.
\end{abstract}

\section{Keywords}

Sports Tracker, Device Dependence, Resilience, Self-Regulatory Modes, Running Agonistic Experience

\section{Introduction}

Wearable technology is spreading more and more in the global market, achieving considerable success, especially in the sports and fitness sectors, becoming essential for those who love sports and need, in real time, to learn fundamental information such as the time and distance traveled, the position in which he/she is located, the heart rate and effort made, the calories consumed, and other spe- 
cific parameters to check the reactions of the body subjected to prolonged effort and monitor individual athletic performance (Wang et al., 2016; Coughlin \& Stewart, 2016; Henriksen et al. 2018; Godfrey et al., 2018). The wearable tech is currently offered in various forms, from the classic watch to the smart bracelet, from fitness bands to sensors of every shape and nature, to monitors indicating the physical performances useful in different sports, and thanks to their ability to connect to digital multimedia technology or to a smartphone, they are able to manage the data relating to the activity so as to be able to keep a real archive, with which to constantly monitor the progress achieved and obtainable (Rabin \& Bock, 2011; Kinnunen et al., 2012; Kaewkannate \& Kim, 2016; Hanton et al., 2017; Leone, 2018). Among the lovers of the race can be distinguished two categories of runners, the "jogger" and the "runners" that, unlike the first, train intensely in order to compete in sporting events in a systematic way (Schenkenfelder \& Selinger, 2016). For "joggers" the use of a simple smartphone could be sufficient, as long as it is equipped with the GPS antenna to accomplish the monitoring mission very well while running or walking (Aughey, 2011; Seshadri et al., 2019). When running on the other hand goes beyond being in shape, it becomes essential to use more particular instruments, that is "sport tracker", wearable at an advanced level, which can improve the quality of the training and the ability to make information more complete and detailed of those provided by smartphone applications, not able to guarantee that effectiveness and efficiency necessary for carrying out increasingly complex physical exercises (Janssen et al., 2017; Wang, 2015).

Competitive and professional athletes, who carry out intensive training, have very different needs from those of a "jogger" runner, as well as having the need for a clock with repetitive timer, chronometer with intermediate times and speed and distance function, personal diary suitable for memorizing all the training sessions carried out with the relative times and speeds obtained, allowing an immediate comparison of performance between one session and the previous one, and naturally the function that monitors the heart muscle (Case et al., 2015; Phan et al., 2015). The GPS integrated in the device provides precise calculations regarding speed, distance, altitude and allows the runner to observe the route on the map after the running session (Cummins et al., 2013; Pobiruchin et al., 2017). The altimetry of the route is automatically detected as well as the maximum height difference during training and the race are directly visible in real time on the display of the device, like many other fundamental parameters (Bpm, distance, cardio, calories, etc.) (Crouter, 2004). An added value of most sports trackers is the ability to view statistics either in real time, while running or after training is finished on the computer monitor or directly on the watch display (Evenson et al., 2015). For example, the times of each $\mathrm{km}$ can be recorded with real-time statistics on distance and timing, and it is possible to set an audible warning after each kilometer or a particular heart rate value (Li et al., 2016; Aroganam et al., 2019). In addition can be shared workouts with followers, and 
then relive the sessions of their own and others' training on all digital multimedia devices (PCs, smart-phones, tablets, etc.), in short, keeping a real open window to the world and talking, sharing, exchanging experiences and feelings for a constant personal, social and competitive growth (Stragier et al., 2015; Chang et al., 2016).

Every athlete who uses a digital device as a support for the running of the race, is progressively aware of so-called advanced functions, as the level of training and preparation increases (Bourdon et al., 2017; Ng \& Ryba, 2018; Goodyear et al., 2019). Preliminarily it can be said that the choice of the device is often dictated by factors external to the activity, such as the purchase price and word of mouth, but once the same is available and one learns to use it, a true and proper dependency bond that hardly a runner can do without wearing his device during training or competitions (Maher et al., 2017; Johnston \& Heiderscheit, 2019). This feeling will be more intense depending on the user's perception of being able to take advantage of a usable and ergonomic device that allows him to exploit his own characteristics and potential to the fullest (Lee \& Drake, 2013). It is not excluded that device also performs for the athlete a function of limiting perceived stress, especially in preparation for the competitions, ensuring through the various monitoring functions, an exercise of control and greater awareness of their performance in situations of pressure (see Foster et al., 2017; Roos et al., 2017; Rieder et al., 2019). Some studies (e.g. Lucidi et al., 2016; Pica et al., 2019) have recently explored in competitive athletes the relationships between regulatory modes and stressful experiences such as the training for a competition or the retirement. For this reason, we have considered it valid for exploratory purposes to examine the relationship between the regulatory mode orientations (locomotion and assessment) and the use of sport devices. A second frequently reported association in the runners' literature is that between perceived stress and resilience (Sarkar \& Fletcher, 2013; Sarkar \& Fletcher, 2014; Codonhato et al., 2018). Athletes who practice endurance sports are well aware that their activity can be critical, causing unexpected events or random factors related to their physical and mental state. Resilience for an athlete is the ability to resist pursuing challenging goals, effectively coping with the difficulties and adverse moments encountered along the way, facing frustrations, and stress after a negative event such as defeat. Being resilient also means being able to recognize one's limits and accept them, and have the strength to look beyond difficulties optimistically (see Gerber et al., 2013; Fletcher \& Sarkar, 2013; Galli \& Gonzalez, 2015; Fletcher \& Sarkar, 2016). Considering this, we wanted to explore if athlete's dimensions of the resilience (according to Richardson's model of 2002) were related to the mode of use of the sport device. The mode of use, as indicated by Schukat et al. (2016), could configure a bond with the device that can also be structured as a proper dependency bond. Users may become obsessed with self-monitoring beyond what can be considered a healthy level of attention to oneself. Individual reports of addictive behaviors regarding wearable fitness 
devices used by healthy individuals (see Attig \& Franke, 2019) provide insight into the unintended power that these devices yield and how they can shape the way users manage their daily life. Consequently we decided to test whether in agonistic runners regulatory modes orientation and the resilient capability both showed a particular relationship amongst themselves, and with the device dependency. As far as we are aware, there have been no previous studies dealing with the relationship between individual differences (regulatory modes orientation and resilience dimensions) and experience of device use.

\section{Procedure}

\subsection{Hypotheses}

Sport experience would significantly impact the use and the experience with sports monitoring devices. Therefore first hypothesis put to the test was that the level of experience of the runner would be associated with the way of use and with a diversified appreciation of the functions of the device. Through the analysis of the percentage frequencies of use of the functions, it was expected that, of the numerous functions offered by the most common devices, only a limited number would actually be used, and that among these the hierarchy of use would change in relation to the level of experience of the runner. Secondly, individual differences (in particular regulatory modes orientation and resilience dimensions of the subjects) would in turn be significantly associated amongst themselves, and with the experience of using the device itself (specifically with dependence experiences). It was expected to find such evidence from correlational and variance analysis.

\subsection{Tools}

In order to collect the data necessary to carry out the study a questionnaire was built up and articulated into the following sections: 1) socio-demografic info: gender; age; 2) specifications as a runner: athletic specialty, i.e. $10 \mathrm{~km}$, half marathon, marathon, cross country; years of experience in agonistic running; 3 ) opinion on the preponderant factor for a good agonistic preparation: choice between careful planning, intensive training, continuous monitoring, 4) use of the sport tracker device: perceived utility ( 1 - 5 points from useless to essential); frequency of use of each function (ones most frequently used-multiple response); satisfaction with basic and advanced functions ( 1 - 5 points from very low to very good); evaluation of usability and device ergonomics: precision, ease of use, quality/price ratio, reliability, completeness, aesthetics, handling skills (1 - 5 points from very low to excellent, Cronbach's alpha .75); 5) expectations on the device: it could help to further improve its own performances ( 1 - 5 points from completely disagree to completely agree); 6) psychometric measurements: a) Regulatory-Modes Scale (RMS; Higgins et al., 2003; Pierro et al., 2006) composed of 24 items (12 for the measure of Assessment Mode and 12 for the measure of Locomotion Mode) 6-points Likert (from 1 = completely disagree to $6=$ 
completely agree). In this study Cronbach's alpha resulted .80. Assessment is the comparative component of the system of regulation of the Self, as a tendency to critically assess the state in which we are in relation to other alternatives for to achieve the goals in the best possible way. The Locomotion, on the contrary, is the component of our self-adjusting system dedicated to control the movement by state and its maintenance to achieve an objective in a simple way and without distractions or delays. In this study Cronbach's alpha resulted .67; b) The Resilience Process Questionnaire (RPQ; Laudadio et al., 2011) consists of 15 items based on a five-step Likert scale ( $1=$ disagree; $5=$ totally agree). It deepens three dimensions of resilience, according to Richardson perspective (2002): i) Resilient Recovery. typical of a subject who is able to overcome traumatic or stressful events: scores above 8 are associated with a strong resilience of the subject. E.g.: "I think that a painful situation can make me better"; Cronbach's alpha in this study resulted .83; ii) Return to Homeostasis. scores above 8 are characteristic of subjects who, in the face of the trauma, try to restore the state of equilibrium before the event. E.g.: "When I am in a difficult situation, I do everything to regain the strength I had"; Cronbach's alpha in this study resulted .84; iii) Reintegration with Loss. scores above 8 indicate the difficulty in facing, accepting and overcoming traumatic or stressful events. In this dimension, the test authors also included Dysfunctional Recovery (Richardson, 2002). e.g.: "When something bad happens to me, I cannot get a reason"; Cronbach's Alpha in this study resulted .75. c) In order to assess addiction bond with the device a Dependency Index on the tracker device has been constructed taking into account the overall averages of the scores for the following four questions (Likert 1 - 5): i) "If you could not have your device with you, would you still train?"; ii) "If you were to be unable to use your device during training, how much discomfort do you think this would cause?"; iii) "How much do you feel tied to the use of your device?"; iv) "Do you think that at this moment your sporting performance is influenced by the use of your device?". The index was subjected to an PCA exploratory verification and showed a monofactorial structure, Determinant .192, KMO .709, Rotated Component Matrix Oblimin, Test Bartlett Sphericity sig. .000. The index has demonstrated good reliability by presenting a Cronbach's alpha coefficient equal to .79 .

\subsection{Sample Selection and Questionnaire Administration Procedures}

The data necessary to verify the working hypotheses were collected through the administration of a questionnaire specifically structured to a representative sample of athletes on a regional scale, all strictly accumulated by the performance of competitive activities supported by the use of digital wrist devices for monitoring of individual performances. The reference population concerned runners belonging to the 15 running sports associations of the Province of Frosinone, members of the Fidal (Italian Athletics Federation), which in June 2019 registered 794 athletes. The sample size determination was made by setting a 1-alpha 
confidence level at $95 \%$, therefore with $\mathrm{z}$ normal value at the confidence level of 1.96. The following two formulas were applied, where the second operated the correction for small populations (<20,000): 1) $X_{o}=z^{2}\left(p^{*} q\right) / b^{2}$, with $p$ as the proportion to be estimated and $q$ the proportion of complementary character and $\mathrm{b}$ the desired precision set at $7 \%$. Hence: $3.8416(0.84 * 0.16) / 0.0045=143.41 ; 2)$ $X=X_{o} /\left[1+\left(X_{o} / p o p\right)\right]$, with pop the numerical value of the reference population. Hence: $143.41 /[1+(143.41 / 794)]=105.36$. Participants were recruited through a preliminary contact with the presidents of the running sports associations, who ensured the dissemination of the questionnaire to their members, through the forwarding of an email in which they were indicated the objectives and purpose of the study and in which, at the same time, subjects were invited to access a special link contained in the same communication and then to fill in and transmit the answers in digital and telematic mode. Participants were assured anonymity and the use of data in aggregate form for research purposes only. The average length of time for the compilation was about 20 minutes. One month after the first email was sent, the sample was asked again, both through a resubmission of the mail containing the link to access the questionnaire, and through individual contacts activated with athletes during running competitions held in the region Lazio in July and August 2019. A total of 111 questionnaires were collected. The response rate of the subjects to the submission of the compilation link was rather modest (1:7), but compatible with the fixed sample size $(111>105)$.

\subsection{Statistical Analysis}

The data were processed using the statistical software SPSS version 22. The main analyzes performed were: descriptive statistics to illustrate socio-demografic info, specifications as a runner, opinion on a good agonistic preparation, use of the sport tracker device; Pearson and Spearman bivariate correlations for all main measures (Device Dependence, Running Experience, Regulatory Modes, Resilience) significant at $p<.005$ and at $p<.001,2$-tailed); PCA (Principal Component Analysis) as exploratory factor verification for Dependence Index; Cronbach's alpha as scale reliability coefficient; Anova univariate test with Post-hoc Tukey HSD and $p<.05$ to explore significances between Running Experience, Devise Dependence, Regulatory Modes and Resilience.

\section{Results}

\subsection{Descriptive Analysis}

There were a total of 111 participants (Males $=93(83.8 \%)$; Females $=18(16.2 \%)$. The age of the sample was between 20 and 65 years $(M=43.32$; $S D=8.92)$. The experience in running ranged from 1 to 34 years $(M=7.96$; $S D=7.35)$. In relation to the preferred athletic specialty, the $51.4 \%$ declared to compete desirably for races of $10 \mathrm{~km}$, the $27 \%$ for the half marathon, the $16.2 \%$ for the marathon, the $5.4 \%$ for the cross-country race. Overall the $47.7 \%$ of the sample declared to have competed in at least one marathon in the last three years. Where it was 
asked to indicate a preponderant factor for a good preparation for race, the $57.7 \%$ indicated careful planning, the $27.9 \%$ intensive training, the $13.5 \%$ continuous monitoring of performance.

\subsection{Running and Digital Devices}

When asked about the weight of the digital device for the preparation of the race, only a small portion of subjects said that the use of the tracker was not very useful (7.2\%) or even useless (1.8\%), while for all the others digital devices were deemed quite useful (45.0\%), necessary (31.5\%) or indispensable (13\%). With regard to the type of device used, $41.4 \%$ of the subjects declared to own a Garmin brand device, 20.7\% Polar, 9.8\% Timex, 7.2\% Tom Tom, the remaining subjects referred to devices that covered percentages of less than $3 \%$.

\subsection{Use of the Device Functionalities}

With regard to the distribution of the functions mainly used, sorted by frequency ("Of the following functions, please indicate which ones you use most frequently"-multiple response), it was possible to observe (see Figure 1) that out of 15 functions considered, 5 covered the percentage ranging from $85.6 \%$ to $36 \%$ (calculation of distance, stopwatch, heart rate measurement, activity diary and calculation of calories burned). The remaining functions covered a percentage ranging from $25 \%$ to $0.9 \%$.

Crossing the levels of competitive experience (quartiles of the total years of participation in competitive races) with the frequency of use of device functions, the following variations in percentage resulted, as shown in Figure 2.

First level (1 - 3 years): calculation of distance 96.3; chronometer 81.1; activity diary 44.4; heart rate measurement 40.7; calculation of calories burned 40.7; remaining functions ranged from a percentage of $22.2 \%$ to 0 .

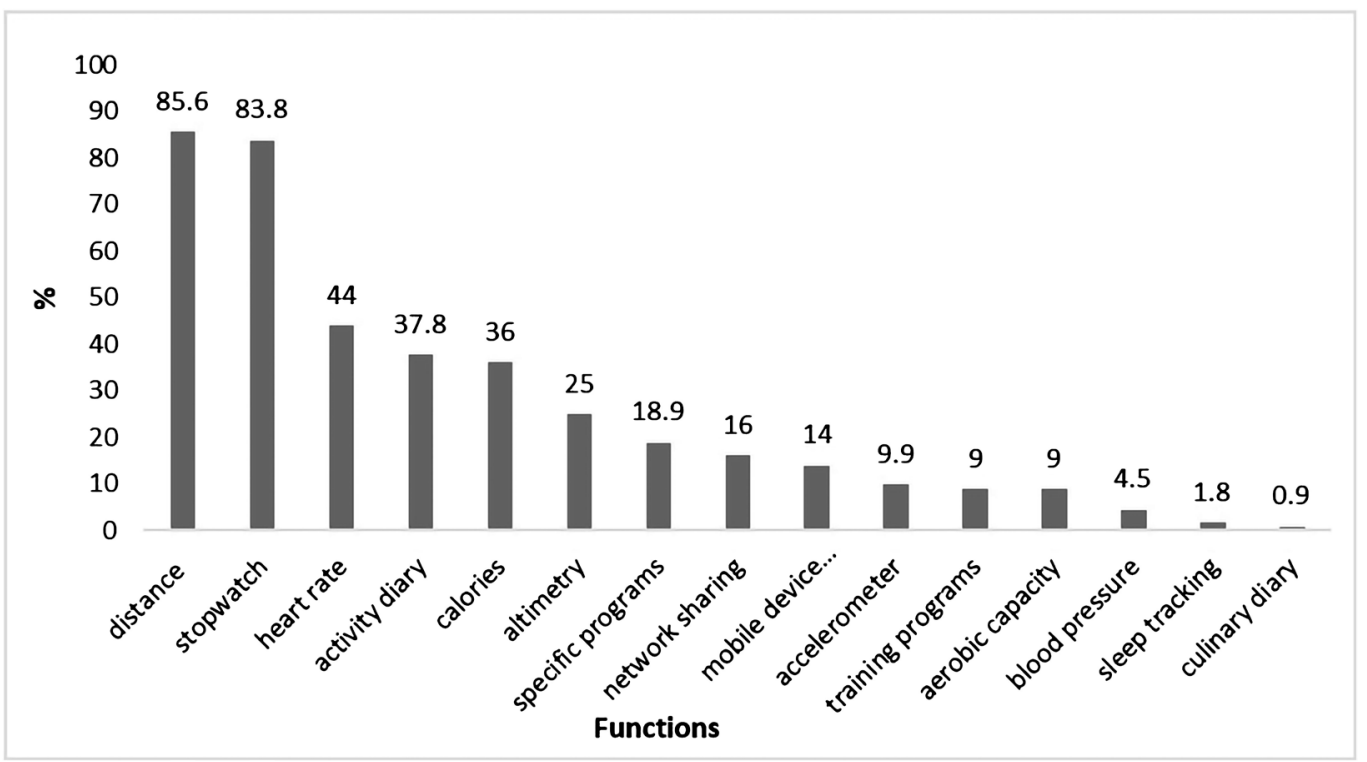

Figure 1. Prevalent use rates of device functions. 


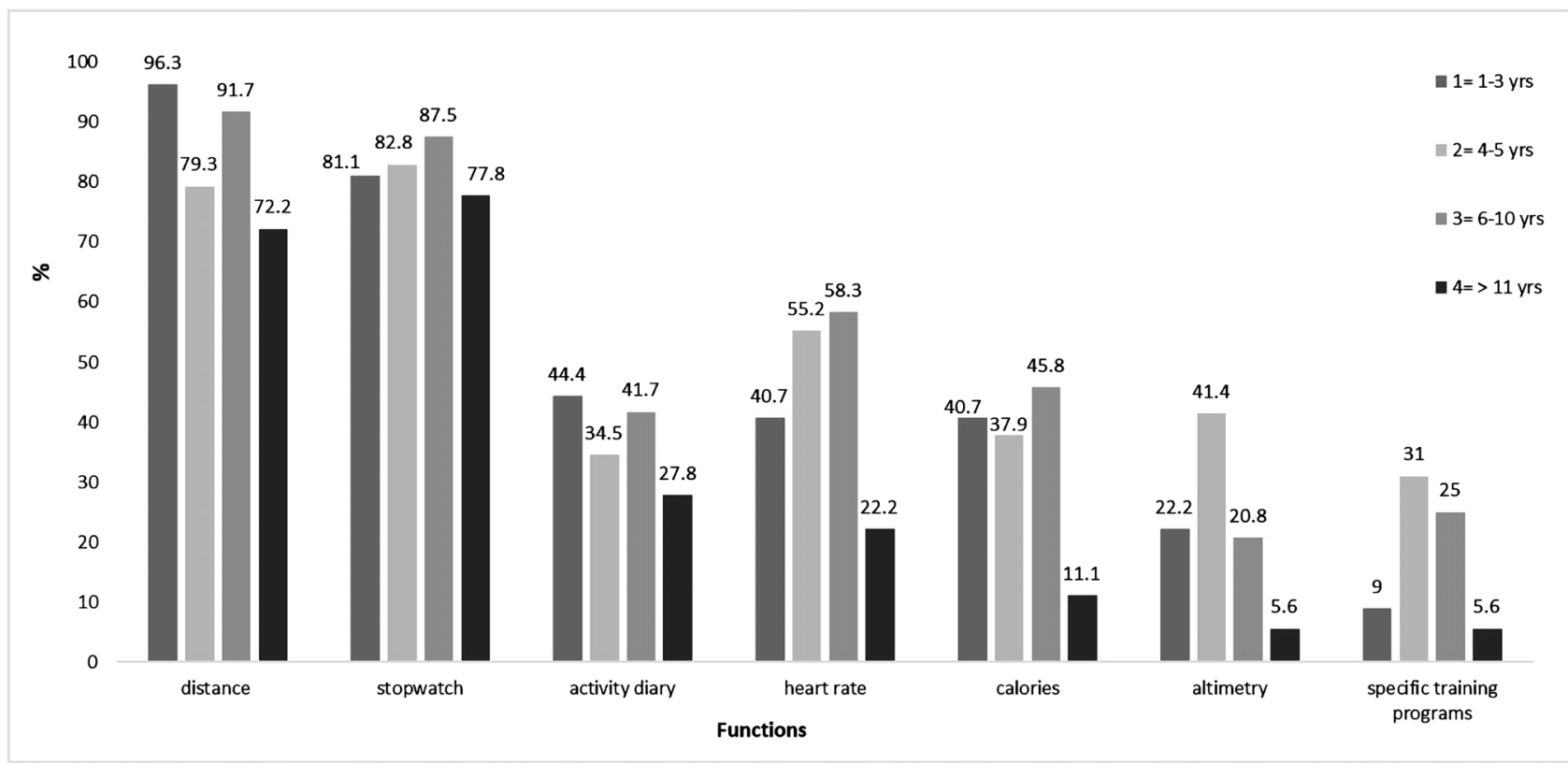

Figure 2. Competitive experience and use of devise functions.

Second level (4 - 5 years): chronometer 82.8; distance 79.3; heart rate 55.2; altimeter 41.4; calculation of calories burned 37.9; diary of activities 34.5 ; training programs 31.0; remaining functions ranged from a percentage of $13.8 \%$ to 0 .

Third level (6 - 10 years): distance 91.7; chronometer 87.5; heart rate 58.3; calories burned 45.8; activity diary 41.7; training programs 25.0; altimeter $20.8, \%$; remaining functions ranged from a percentage of 12.5 to 0 .

Fourth level (over 11 years): chronometer 77.8; distance 72.2; remaining functions ranged from a percentage of 27.8 to 0 .

Among the functions declared as less used by the athletes resulted: sleep tracking $(76.7 \%)$, culinary diary monitoring $(67.7 \%)$, blood pressure measurement $(57.7 \%)$, accelerometer (51.4\%), aerobic capacity measurement (45\%), performance network sharing (43.2\%), specific training analysis programs (37.8\%), mobile device association (36.9\%), altimeter (36.9\%).

The satisfaction degree in using basic functions of the device was rated for the 24.5\% "very good", $62.3 \%$ "good", $11.30 \%$ "sufficient", and only for the $0.9 \%$ respectively "low" and "very low". If considering the different competitive experiences, the trend has instead shown a significant decrease in satisfaction in the fourth level, falling to a minimum percentage of 11.1 .

Satisfaction in using advanced functions was for the 15\% "very good", $57.4 \%$ "good", 19.80\% "sufficient", and 3\% and 4\% respectively "low" and "very low". Also here, the comparative analysis of the data referred to the experience showed a significant decrease in satisfaction in the level 4 , in particular the figure of maximum satisfaction falls to a minimum with a percentage of 11.0 , while for the judgment "good" at 38.9\%, also appeared the level "very low" which was $11.1 \%$.

As regards the evaluation of the quality of usability and ergonomics of the de- 
vice (precision, ease of use, quality/price ratio, reliability, completeness, aesthetics, handling skills) it was noted that almost all of them were appreciated by almost all of the sample. The positive judgment showed, however, a lowering with the growth of the experience, since the percentages moved towards the indication of sufficiency, compared to that of "good" and "excellent".

For $63.1 \%$ of the sample, however, there was a defect in their own device that should be corrected and in particular it has been indicated more problems of night brightness and inconvenience to the strap. The percentage has risen considering the experience gained by the athletes, the most experienced group declares in fact for $83.3 \%$ the presence of defects to be corrected.

\subsection{Device Dependence and Individual Differences}

Following Table 1 reports Pearson's correlation coefficients for the main variables considered in the study.

Considering the hypotheses of the study, worthy of attention was first of all the negative coefficient $-.259^{* *}$ that associated Resilient Recovery and Device Dependence. A strong positive link $\left(.460^{\star *}\right)$ resulted between Resilient Recovery and Locomotion Regulatory Mode, while a remarkable negative link (-.289**) associated Resilient Recovery with Assessment Regulatory Mode. Assessment also showed a strong positive link $\left(.397^{\star *}\right)$ with the Dysfunctional Recovery.

Table 2 shows the average values of the variables being measured in our sample of runners: Device Dependence, Regulatory Modes and Resilience.

\subsection{Running Experience and Devise Dependence}

The Anova test compared experience levels showing a significant difference between the dependency averages of the fourth and second groups. $F(3,107)=$ $4.766 p=.004 \mathrm{Eta}^{2}=.12 \mathrm{OP}=.891$. The group with the most experience (more than 10 years of competitive practice) was less dependent, especially compared to the group of those who fell within the range of 4 to 6 years of competitive

Table 1. Correlation matrix for all main measures of the study.

\begin{tabular}{|c|c|c|c|c|c|c|c|c|}
\hline & $\begin{array}{c}\text { Device } \\
\text { Dependence }\end{array}$ & Age & $\begin{array}{l}\text { Running } \\
\text { Experience }\end{array}$ & $\begin{array}{l}\text { Locomotion } \\
\text { Mode }\end{array}$ & $\begin{array}{l}\text { Assessment } \\
\text { Mode }\end{array}$ & $\begin{array}{l}\text { Hom. } \\
\text { Rec. }\end{array}$ & $\begin{array}{l}\text { Dys. } \\
\text { Rec. }\end{array}$ & $\begin{array}{l}\text { Resilient } \\
\text { Recovery }\end{array}$ \\
\hline Device Dependence & 1 & & & & & & & \\
\hline Age & -.154 & 1 & & & & & & \\
\hline Running Experience & -.086 & $.335^{* *}$ & 1 & & & & & \\
\hline Locomotion Mode & -.133 & .016 & -.004 & 1 & & & & \\
\hline Assessment Mode & .084 & -.066 & .051 & $-.296^{* *}$ & 1 & & & \\
\hline Homeostatic Recovery & -.082 & -.053 & .086 & $.474^{\star *}$ & $-.211^{\star}$ & 1 & & \\
\hline Dysfunctional Recovery & .021 & .127 & .016 & -.114 & $.397^{\star *}$ & $-.470^{\star *}$ & 1 & \\
\hline Resilient Recovery & $-.259^{* *}$ & .133 & .096 & $.460^{* *}$ & $-.289^{\star *}$ & $.539^{* *}$ & -.081 & 1 \\
\hline
\end{tabular}

Note: Pearson's correlation matrix for the means of the scales with the exception of Age and Running Experience, for which the Spearman coefficient was used $\left(n=111 ;{ }^{* *}\right.$, correlation is significant at $P<.0052$-tailed; ${ }^{*}$, correlation is significant at $p<.0012$-tailed). 
Table 2. Mean values of device dependence, regulatory modes and resilience (Sample: N $=111)$.

\begin{tabular}{ccccc}
\hline & Mean & SD & Sk & Ku \\
\hline Device Dependence & 2.49 & .89 & .087 & -.546 \\
Locomotion Mode & 5.16 & .58 & -.276 & -.491 \\
Assessment Mode & 2.87 & .88 & .012 & -.320 \\
Homeostatic Recovery & 3.92 & .62 & .094 & -.858 \\
Dysfunctional Recovery & 2.15 & .51 & .042 & -.078 \\
Resilient Recovery & 3.19 & .83 & .300 & -.290 \\
\hline
\end{tabular}

Legend: $\mathrm{SD}=$ Standard Deviation; Sk = Skewness; Ku = Kurtosis.

practice. Post-hoc Tukey HSD $p<.05 \mathrm{M}_{2}=2.83 \mathrm{SD}=.15 \mathrm{M}_{4}=1.99 \mathrm{SD}=.17$ $95 \%$ CI $[.252 ; 1.43]$. An equally significant result emerged between the two groups (fourth and second) in relation to the expectation that the use of the device could contribute to further improve their own performance: $\mathrm{F}(3,107)=$ $4.094 p=.009 \mathrm{Eta}^{2}=.11 . \mathrm{OP}=831$. The group with competitive experience $4-6$ years attributed more weight to the contribution that the device could continue to exert on their performance level. Post-hoc Tukey HSD $p<.05 \mathrm{M}_{2}=2.48 \mathrm{SD}$ $=.19 \mathrm{M}_{4}=2.50 \mathrm{SD}=.2295 \% \mathrm{CI}[.413 ; 1.56]$.

\subsection{Regulatory Modes and Resilience}

Worthy of attention was the difference resulted between average values of Locomotion Regulatory Mode $(\mathrm{M}=5.16)$ and Assessment Regulatory Mode $(\mathrm{M}=$ 2.87) stressing that in the sample of runners the orientation towards the objective with respect to the evaluation/control of the process was particularly pronounced. Comparing average values of both scales with other samples of non-competitive subjects, it was possible to note that values of Locomotion Regulatory Mode in runners were significantly higher than those of non-competitive subjects, while the values of Assessment Regulatory Mode tended to be lower: runners sample: $\mathrm{M}_{\text {Loc }}=5.16$ and $\mathrm{M}_{\text {Ass }}=2.87$; mixed adults and young people sample: $\mathrm{M}_{\text {Loc }}=3.82$ and $\mathrm{M}_{\text {Ass }}=3.57$; university students sample: $\mathrm{M}_{\mathrm{Loc}}=3.93$ and $\mathrm{M}_{\text {Ass }}=3.15$ ).

In our sample the runners with the highest target orientation (Locomotion Regulatory Mode) were also those who showed significantly higher values of Resilient Recovery. F $(1,109)=16.325 p=.000 \mathrm{Eta}^{2}=.14 \mathrm{OP}=.98 \mathrm{M}_{1}=2.87 \mathrm{SD}$ $=.66 ; \mathrm{M}_{2}=3.50 \mathrm{SD}=.88 .95 \% \mathrm{CI}[-.938 ;-.320]$. Furthermore runners with the highest target orientation (Locomotion Regulatory Mode) were also those who showed significantly higher values of Omeostatic Recovery. F $(1,109)=10.4 p$ $=.002 \mathrm{Eta}^{2}=.09 \mathrm{OP}=.88 \mathrm{M}_{1}=3.77 \mathrm{SD}=.55 ; \mathrm{M}_{2}=4.14 \mathrm{SD}=.63 .95 \% \mathrm{CI}$ [-.604; -.140]. In addition the runners with the highest process control orientation (Assessment Regulatory Mode) were also those who showed significantly higher values of Dysfunctional Recovery. F $(1,109)=9.825 p=.002 \mathrm{Eta}^{2}=.08$ $\mathrm{OP}=.87 \mathrm{M}_{1}=2.03 \mathrm{SD}=.48 ; \mathrm{M}_{2}=2.33 \mathrm{SD}=.48 .95 \% \mathrm{CI}[-.485 ;-.109]$. 
Lastly the runners with the highest process control orientation (Assessment Regulatory Mode) were also those who showed significantly lower values of Resilient Recovery. F $(1,109)=6.052 p=.015 \mathrm{Eta}^{2}=.05 \mathrm{OP}=.68 \mathrm{M}_{1}=3.34 \mathrm{SD}$ $=.80 ; \mathrm{M}_{2}=2.95 \mathrm{SD}=.82 .95 \% \mathrm{CI}[.075 ; .697]$.

\subsection{Device Dependence and Resilience}

For the purposes of this study, the significant association that emerged between Device Dependence and Resilient Recovery of the athlete was particularly relevant: $\mathrm{F}(1,109)=12.612 p=.001 \mathrm{Eta}^{2}=.10 . \mathrm{OP}=.94$. The increased dependence was significantly associated with lower levels of resilient recovery: $\mathrm{M}_{1}=2.77 \mathrm{SD}$ $=.80 ; \mathrm{M}_{2}=2.20 \mathrm{SD}=.89 .95 \% \mathrm{CI}[.254 ; .894]$ (See Table 3 ).

\section{Discussion}

Worth of interest is underline the relationship between the judgment on the utility of the device for the preparation of the competition and the specific use of the functions: on the one hand the growth of the competitive experience increases the belief that the devices are essential (from $7.7 \%$ to $33 \%$ ), at the same time the number of functions constantly used by users decreases over time (5 functions for the first level of experience, 7 respectively for the second and third level, 2 for the fourth level). The trend suggested that functions are first "discovered", then consolidated and finally subjected to strict selection. Evidently most experienced subjects acquire over time a progressive mastery and (internal control) of their own performative functions. As far as the passage from the first to the second experience level was concerned, it could be observed that hierarchical weight between the calculation of the distance and the chronometer were reversed. Reasonably the subject after having measured, in a first phase, primarily with the distance, then values the running time and it is in this second moment that the need to monitor the heart rate is added, in order to modulate the running speed looking for his own physical limit. At the same time, it is possible to detect the appearance of two complementary functions, the altimeter and the

Table 3. Mean values of dependence, regulatory modes and resilience according to the level of running experience.

\begin{tabular}{|c|c|c|c|c|c|c|c|c|c|c|c|c|c|c|c|c|}
\hline Running Experience & Le & el $1(1$ & - 3 Yea & rs) & Lev & 22 & -6 Yea & rs) & Lev & 3 & -9 Yea & rs) & & el 4 & 10 Yea & \\
\hline N Total: 111 & \multicolumn{4}{|c|}{$\mathrm{n}: 27$} & \multicolumn{4}{|c|}{$\mathrm{n}: 34$} & \multicolumn{4}{|c|}{$\mathrm{n}: 24$} & \multicolumn{4}{|c|}{$\mathrm{n}: 25$} \\
\hline Device Dependence & 2.54 & .83 & .026 & -.263 & 2.83 & .66 & -.486 & .414 & 2.60 & .89 & .124 & -.666 & 1.99 & .98 & 1.10 & 1.24 \\
\hline Locomotion Mode & 5.11 & .59 & .307 & -1.17 & 5.15 & .52 & -.190 & -.755 & 5.18 & .66 & -.866 & .904 & 5.19 & .60 & -.291 & -.667 \\
\hline Assessment Mode & 2.99 & 1.00 & -.286 & -.541 & 2.90 & .81 & .042 & -.507 & 2.78 & .63 & .154 & -.985 & 2.87 & 1.00 & .204 & -.132 \\
\hline Homeostatic Recovery & 3.95 & .69 & .038 & -.872 & 3.88 & .61 & -.023 & -.881 & 3.89 & .54 & .197 & -.618 & 3.91 & .63 & .209 & -.927 \\
\hline Dysfunctional Recovery & 2.23 & .61 & -.014 & .075 & 2.17 & .44 & -.270 & -.377 & 1.96 & .47 & .486 & .684 & 2.23 & .50 & -.310 & -.149 \\
\hline Resilient Recovery & 3.24 & .92 & .363 & -.797 & 3.07 & .90 & .334 & -.140 & 3.11 & .64 & .314 & -.055 & 3.30 & .72 & .069 & .088 \\
\hline
\end{tabular}

Legend: $\mathrm{SD}=$ Standard Deviation; $\mathrm{Sk}=$ Skewness; Ku = Kurtosis. 
specific training programs. Obviously, the runner need additional information and support to obtain the best athletic performance. At the third level of experience it could be seen that again the hierarchical weight between distance and chronometer is reversed. The new priority acquired by the extension of the distance is associated with a new increase in the function of control of burned calories, as exceeded the distance of 20 kilometers, necessarily requires a continuous caloric replenishment to continue in conditions of efficiency. At the fourth level, priority is given to the chronometer and distance functions for the reasons mentioned above. With reference to the satisfaction in the use of both basic and advanced functions of the device, a progressive critical judgment could be detected in the most expert group, probably due to the fact that outside the functions considered indispensable, the others no longer corresponded to their explicit need. As far as the evaluation of the quality of usability and ergonomics of the device was concerned, it was noted that they were appreciated by almost the entire reference sample. In relation to the detection of defects detected in the devices as experience grows, there was a greater propensity to indicate the presence of defects to be corrected. Specifically, problems relating to night-time illumination of the device and to the wrist strap were more widely reported. With regard to the section that intended to assess the bond with the device, it is worthy of attention the fact that describes the discomfort caused by not being able to use own device. The highest dependence was found in runners with competitive experience between 4 and 6 years, while the lowest average dependence was found in runners with the highest experience ( $>10$ years). In relation to the judgment on the influence of the device on sports performance, resulted a progressive decrease in the weight of the perceived influence related to the growth of the experience. This result can be interpreted as a consolidation of one's awareness and active control role in the management of one's performance. In other words, they do not deny the use of the device, but claim to "use" it as an aid, considering themselves the only protagonists for the achievement and improvement of their athletic performance. A plausible interpretation is that the "independents" are the subjects who have acquired greater autonomy in monitoring their competitive performance, while the "dependents" are subjects strongly linked to the indispensability of support in monitoring ensured by the device.

With regard to the weight of individual differences, significance has emerged in the measurement of the resilient capacity of the subjects. Resilient Recovery is the resilience dimension that has shown a remarkable inverse relationship with the device dependency. Among the regulatory modes the Locomotion orientation revealed an interesting link with the Resilient Recovery, while the Assessment mode was associated with the Dysfunctional Recovery. These associations that have emerged in the study suggest a potential explanatory articulation that could be the subject of a further model investigation. Considering the articulation into levels of experience, it appeared that the second and third levels were composed of subjects with a higher component of resilient recovery. The orien- 
tation to the objective (locomotion mode) of the athletes, resulted significantly associated with the function of sharing the own performances on internet. Evidently, the subjects most focused on their own objectives were aware that the interaction and sharing, was a useful tool for further growth and pursuit of their final objectives. The need for control in the process can turn out, in some cases, to be excessively rigid, preventing the subject from focusing attention on the dynamism of the purpose-oriented process, crystallizing the projection of attention on the internal control components. Having control of the situation does not mean being obsessively focused on the details in order not to let anything escape, on the contrary, a resilient subject manifests his sense of control by showing some flexibility in the face of unexpected events, whether they be negative or positive. Numerous studies have already consolidated the hypothesis of a greater effectiveness in performative terms of the outsourcing of the focus of attention (see Schücker et al., 2009; Neumann \& Piercy, 2013; Zep Iin et al., 2014). Therefore, a goal setting with a pronounced internal focus component can produce less significant final results compared to a focus orientation of the attention decidedly oriented towards the objective.

\section{Conclusion}

The results of the study supported the initial hypothesis that the level of competitive experience was a determining variable in modulating the strategy of use of digital devices. Participants expressed very positive usability evaluations of both the functions and the device as a whole, revealing the development of a progressive interaction between the opportunities offered by the functions and the specific needs of the athlete. The association of some specific individual trait with the experience of using the device was confirmed. It was also confirmed the influence that subjects attributed to the device on individual athletic performance and the overall impact on the personal and relational sphere of the subject. In conclusion, the profile of the agonist runner revealed a pronounced orientation to the objective which constituted a primary focus of attention for all the subjects. This provision also influences the normal relations of use of the digital device in the face of a recognized functionality and usefulness of the same, the subject is sufficiently autonomous to structure the relationship of use in strictly instrumental function, so that in the face of a wide response in terms of diffusion of the devices, there is no perception of dependence or "subjugation", rather the subject is well aware that the appropriate and intelligent use can promote the achievement of clear objectives and predetermined with full awareness by the most experienced runner. On the other hand, it was possible to observe a relatively more "passive" attitude towards the monitoring tool in subjects who belonged to the levels of minor experience or in those subjects whose individual profile showed higher values in the assessment regulatory mode, which corresponds to an attitude of goal-setting oriented more towards the evaluation and interpretation of the individual performative moments. 


\section{Limitations}

The study certainly has some limitations. The first is related to the modest number of participants. A replication of the study with a wider sample base would be desirable so that further inferential statistics and structural testing can be used to investigate the predictive weight of resilience variables and regulatory modes on device dependence in the runner. It is also likely that significant variables not considered in this study, such as the components of anxiety (somatic, cognitive and social) or the level of stress perceived by the athlete, will also come into play in the relationship with addiction. It would be appropriate to think of a replication of the study by assessing the incidence of these additional components or other specifications related to the context (including cultural attitudes) in which the athlete operates. Given the widespread use of sports trackers in many sports disciplines, it would also be reasonable to undertake exploratory and comparative studies on sports device addiction in other disciplines than running.

\section{Authors' Contributions}

PD, SM, and SC designed the study. PD, SC, and SM analyzed the data and discussed the results. PD and SC drafted the manuscript, and SM and SC revised the manuscript. All authors approved the final manuscript. Finally, the authors have agreed to be accountable for all aspects of the manuscript in ensuring that questions related to the accuracy or integrity of any part of it are appropriately investigated and resolved.

\section{Conflicts of Interest}

The authors declare no conflicts of interest regarding the publication of this paper.

\section{References}

Aroganam, G., Manivannan, N., \& Harrison, D. (2019). Review on Wearable Technology Sensors Used in Consumer Sport Applications. Sensors, 19, 1983. https://doi.org/10.3390/s19091983

Attig, C., \& Franke, T. (2019). I Track, Therefore I Walk-Exploring the Motivational Costs of Wearing Activity Trackers in Actual Users. International Journal of HumanComputer Studies, 127, 211-224. https://doi.org/10.1016/j.ijhcs.2018.04.007

Aughey, R. J. (2011). Applications of GPS Technologies to Field Sports. International Journal of Sports Physiology and Performance, 6, 295-310. https://doi.org/10.1123/ijspp.6.3.295

Bourdon, P. C., Cardinale, M., Murray, A., Gastin, P., Kellmann, M., Varley, M. C., \& Cable, N. T. (2017). Monitoring Athlete Training Loads: Consensus Statement. International Journal of Sports Physiology and Performance, 12, 161-170. https://doi.org/10.1123/IJSPP.2017-0208

Case, M. A., Burwick, H. A., Volpp, K. G., \& Patel, M. S. (2015). Accuracy of Smartphone Applications and Wearable Devices for Tracking Physical Activity Data. The Journal of the American Medical Association, 313, 625-626. https://doi.org/10.1001/jama.2014.17841

Chang, R. C. S., Lu, H. P., Yang, P., \& Luarn, P. (2016). Reciprocal Reinforcement be- 
tween Wearable Activity Trackers and Social Network Services in Influencing Physical Activity Behaviors. JMIR mHealth and uHealth, 4, e84. https://doi.org/10.2196/mhealth.5637

Codonhato, R., Vissoci, J. R. N., Nascimento Junior, J. R. A. D., Mizoguchi, M. V., \& Fiorese, L. (2018). Impact of Resilience on Stress and Recovery in Athletes. Revista Brasileira de Medicina do Esporte, 24, 352-356. https://doi.org/10.1590/1517-869220182405170328

Coughlin, S. S., \& Stewart, J. (2016). Use of Consumer Wearable Devices to Promote Physical Activity: A Review of Health Intervention Studies. Journal of Environment and Health Sciences, 2.

Crouter, S. E. (2004). Validity of 10 Electronic Pedometers for Measuring Steps, Distance, and Energy Cost. Medicine \& Science in Sports \& Exercise, 36, 331-335.

Cummins, C., Orr, R., O’Connor, H., \& West, C. (2013). Global Positioning Systems (GPS) and Microtechnology Sensors in Team Sports: A Systematic Review. Sports Medicine, 43, 1025-1042. https://doi.org/10.1007/s40279-013-0069-2

Evenson, K. R., Goto, M. M., \& Furberg, R. D. (2015). Systematic Review of the Validity and Reliability of Consumer-Wearable Activity Trackers. International Journal of Behavioral Nutrition and Physical Activity, 12, 159.

https://doi.org/10.1186/s12966-015-0314-1

Fletcher, D., \& Sarkar, M. (2013). Psychological Resilience: A Review and Critique of Definitions, Concepts and Theory. European Psychologist, 18, 12-23.

https://doi.org/10.1027/1016-9040/a000124

Fletcher, D., \& Sarkar, M. (2016). Mental Fortitude Training: An Evidence-Based Approach to Developing Psychological Resilience for Sustained Success. Journal of Sport Psychology in Action, 7, 135-157. https://doi.org/10.1080/21520704.2016.1255496

Foster, C., Rodriguez-Marroyo, J. A., \& De Koning, J. J. (2017). Monitoring Training Loads: The Past, the Present, and the Future. International Journal of Sports Physiology and Performance, 12, 2-8. https://doi.org/10.1123/IJSPP.2016-0388

Galli, N., \& Gonzalez, S. P. (2015). Psychological Resilience in Sport: A Review of the Literature and Implications for Research and Practice. International Journal of Sport and Exercise Psychology, 13, 243-257. https://doi.org/10.1080/1612197X.2014.946947

Gerber, M., Kalak, N., Lemola, S., Clough, P. J., Perry, J. L., Pühse, U., Elliot, C., Holsboer-Trachsler, E., \& Brand, S. (2013). Are Adolescents with High Mental Toughness Levels More Resilient against Stress? Stress and Health, 29, 164-171.

https://doi.org/10.1002/smi.2447

Godfrey, A., Hetherington, V., Shum, H., Bonato, P., Lovell, N. H., \& Stuart, S. (2018). From A to Z: Wearable Technology Explained. Maturitas, 113, 40-47. https://doi.org/10.1016/j.maturitas.2018.04.012

Goodyear, V. A., Kerner, C., \& Quennerstedt, M. (2019). Young People's Uses of Wearable Healthy Lifestyle Technologies; Surveillance, Self-Surveillance and Resistance. Sport, Education and Society, 24, 212-225. https://doi.org/10.1080/13573322.2017.1375907

Hanton, C. R., Kwon, Y. J., Aung, T., Whittington, J., High, R. R., Goulding, E. H., Bonasera, S. J. et al. (2017). Mobile Phone-Based Measures of Activity, Step Count, and Gait Speed: Results from a Study of Older Ambulatory Adults in a Naturalistic Setting. JMIR mHealth and uHealth, 5, e104. https://doi.org/10.2196/mhealth.5090

Henriksen, A., Mikalsen, M. H., Woldaregay, A. Z., Muzny, M., Hartvigsen, G., Hopstock, L. A., \& Grimsgaard, S. (2018). Using Fitness Trackers and Smartwatches to Measure Physical Activity in Research: Analysis of Consumer Wrist-Worn Wearables. 
Journal of Medical Internet Research, 20, e110. https://doi.org/10.2196/jmir.9157

Higgins, E. T., Kruglanski, A. W., \& Pierro, A. (2003). Regulatory Mode: Locomotion and Assessment as Distinct Orientations. Advances in Experimental Social Psychology, 35, 294-344. https://doi.org/10.1016/S0065-2601(03)01005-0

Janssen, M., Scheerder, J., Thibaut, E., Brombacher, A., \& Vos, S. (2017). Who Uses Running Apps and Sports Watches? Determinants and Consumer Profiles of Event Runners' Usage of Running-Related Smartphone Applications and Sports Watches. PLoS ONE, 12, e0181167. https://doi.org/10.1371/journal.pone.0181167

Johnston, W., \& Heiderscheit, B. (2019). Mobile Technology in Running Science and Medicine: Are We Ready? Journal of Orthopaedic \& Sports Physical Therapy, 49, 122 125. https://doi.org/10.2519/jospt.2019.0604

Kaewkannate, K., \& Kim, S. (2016). A Comparison of Wearable Fitness Devices. BMC Public Health, 16, 433. https://doi.org/10.1186/s12889-016-3059-0

Kinnunen, H., Tanskanen, M., Kyröläinen, H., \& Westerterp, K. R. (2012). Wrist-Worn Accelerometers in Assessment of Energy Expenditure during Intensive Training. Physiological Measurement, 33, 1841. https://doi.org/10.1088/0967-3334/33/11/1841

Laudadio A., Mazzocchetti L., \& Fiz Pérez J. (2011) Valutare la resilienza. Teorie, modelli e strumenti. Roma: Editore Carocci.

Lee, V. R., \& Drake, J. (2013). Digital Physical Activity Data Collection and Use by Endurance Runners and Distance Cyclists. Technology, Knowledge and Learning, 18, 39-63. https://doi.org/10.1007/s10758-013-9203-3

Leone, F. (2018). Using Wearables in Sports and Fitness. Eracle. Journal of Sport and Social Sciences, 1, 5-12.

Li, R. T., Kling, S. R., Salata, M. J., Cupp, S. A., Sheehan, J., \& Voos, J. E. (2016). Wearable Performance Devices in Sports Medicine. Sports Health, 8, 74-78. https://doi.org/10.1177/1941738115616917

Lucidi, F., Pica, G., Mallia, L., Castrucci, E., Manganelli, S., Bélanger, J. J., \& Pierro, A. (2016). Running away from Stress: How Regulatory Modes Affect Stress through Passion. Scandinavian Journal of Medicine and Science in Sports, 26, 703-711. https://doi.org/10.1111/sms.12496

Maher, C., Ryan, J., Ambrosi, C., \& Edney, S. (2017). Users' Experiences of Wearable Activity Trackers: A Cross-Sectional Study. BMC Public Health, 17, 880. https://doi.org/10.1186/s12889-017-4888-1

Neumann, D. L., \& Piercy, A. (2013). The Effect of Different Attentional Strategies on Physiological and Psychological States during Running. Australian Psychologist, 48, 329-337. https://doi.org/10.1111/ap.12015

Ng, K., \& Ryba, T. (2018). The Quantified Athlete: Associations of Wearables for High School Athletes. Advances in Human-Computer Interaction, 2018, Article ID: 6317524. https://doi.org/10.1155/2018/6317524

Phan, D., Siong, L. Y., Pathirana, P. N., \& Seneviratne, A. (2015). Smartwatch: Performance Evaluation for Long-Term Heart Rate Monitoring. In 2015 International Symposium on Bioelectronics and Bioinformatics (ISBB) (pp. 144-147). Beijing. https://doi.org/10.1109/ISBB.2015.7344944

Pica. G., Mallia, L., Pierro, A., Alivernini, F., Borellini, V., \& Lucidi, F. (2019). How Stressful Is Retirement! Antecedents of Stress Linked to Athletes' Career Termination. Journal of Applied Social Psychology, 49, 488-497. https://doi.org/10.1111/jasp.12599

Pierro, A., Kruglanski, A. W., \& Higgins, E. T. (2006). Regulatory Mode and the Joys of 
Doing: Effects of Locomotion and Assessment on Intrinsic and Extrinsic Task-Motivation. European Journal of Personality, 20, 355-375. https://doi.org/10.1002/per.600

Pobiruchin, M., Suleder, J., Zowalla, R., \& Wiesner, M. (2017). Accuracy and Adoption of Wearable Technology Used by Active Citizens: A Marathon Event Field Study. JMIR mHealth and uHealth, 5, e24. https://doi.org/10.2196/mhealth.6395

Rabin, C., \& Bock, B. (2011). Desired Features of Smartphone Applications Promoting Physical Activity. Telemedicine and e-Health, 17, 801-803. ttps://doi.org/10.1089/tmj.2011.0055

Richardson, G. E. (2002). The Metatheory of Resilience and Resiliency. Journal of Clinical Psychology, 58, 307-321. https://doi.org/10.1002/jclp.10020

Rieder, A., Lehrer, C., \& Jung, R. (2019). Understanding the Habitual Use of Wearable Activity Trackers. In 14th International Conference on Wirtschaftsinformatik (pp. 1002-1016). Siegen, Germany.

Roos, L., Taube, W., Beeler, N., \& Wyss, T. (2017). Validity of Sports Watches When Estimating Energy Expenditure during Running. BMC Sports Science, Medicine and Rehabilitation, 9, 22. https://doi.org/10.1186/s13102-017-0089-6

Sarkar, M., \& Fletcher, D. (2013). How Should We Measure Psychological Resilience in Sport Performers? Measurement in Physical Education and Exercise Science, 17, 264280. https://doi.org/10.1080/1091367X.2013.805141

Sarkar, M., \& Fletcher, D. (2014). Psychological Resilience in Sport Performers: A Review of Stressors and Protective Factors. Journal of Sports Sciences, 32, 1419-1434. https://doi.org/10.1080/02640414.2014.901551

Schenkenfelder, R., \& Selinger, S. (2016). A Comparison of Multiple Wearable Devices Regarding Their User Experience during Running.

http://ffhoarep.fh-ooe.at/bitstream/123456789/686/1/125_218_Schenkenfelder_FullPap er_en_Final.pdf

Schücker, L., Hagemann, N., Strauss, B., \& Völker, K. (2009). The Effect of Attentional Focus on Running Economy. Journal of Sports Sciences, 27, 1241-1248. https://doi.org/10.1080/02640410903150467

Schukat, M., McCaldin, D., Wang, K., Schreier, G., Lovell, N. H., Marschollek, M., \& Redmond, S. J. (2016). Unintended Consequences of Wearable Sensor Use in Healthcare. Contribution of the IMIA Wearable Sensors in Healthcare WG. Yearbook of Medical Informatics, No. 1, 73-86.

Seshadri, D. R., Li, R. T., Voos, J. E., Rowbottom, J. R., Alfes, C. M., Zorman, C. A., \& Drummond, C. K. (2019). Wearable Sensors for Monitoring the Internal and External Workload of the Athlete. NPJ Digital Medicine, 2, 71. https://doi.org/10.1038/s41746-019-0149-2

Stragier, J., Evens, T., \& Mechant, P. (2015). Broadcast Yourself: An Exploratory Study of Sharing Physical Activity on Social Networking Sites. Media International Australia, 155, 120-129. https://doi.org/10.1177/1329878X1515500114

Wang, J. B., Cataldo, J. K., Ayala, G. X., Natarajan, L., Cadmus-Bertram, L. A., White, M., \& Pierce, J. P. (2016). Mobile and Wearable Device Features that Matter in Promoting Physical Activity. Journal of Mobile Technology in Medicine, 5, 2. https://doi.org/10.7309/jmtm.5.2.2

Wang, K. L. (2015). Application of Wearable Devices to Running during Training. International Journal of Machine Learning and Computing, 5, 445. https://doi.org/10.18178/ijmlc.2015.5.6.549

Zep Iin, S., Galli, N., Visek, A. J., Durham, W., \& Staples, J. (2014). Concentration and Attention in Sport. SportPsych Works, 2, 1-2. 